\title{
Swallowing Problems in the Normal Ageing Population
}

\author{
Tracey Wilkinson and Janet de Picciotto \\ Department of Speech Pathology and Audiology \\ University of the Witwatersrand
}

\begin{abstract}
This study investigated the prevalence of subjectively reported swallowing problems in a group of normal ageing subjects. Twenty-five retirement village residents were included in the sample. A cross-sectional descriptive survey research design was utilised. Data was obtained through the administration of a devised interview schedule. The prevalence of reported swallowing problems in the sample was determined. The nature of the swallowing problems were examined and compared to those reported to occur in the normal ageing population. The utility of the interview schedule was critically evaluated. Results revealed an overall prevalence of $44 \%$ of subjects who experience swallowing problems that interfere with their day to day functioning. Of these, $64 \%$ experienced swallowing difficulties affecting all phases of the swallow while $36 \%$ experienced difficulties affecting the pharyngeal and oesophageal phases. The interview was found to be a useful screening measure in identifying the presence of swallowing problems. The role of the speech pathologist in dysphagia in the normal ageing population is highlighted and justified.
\end{abstract}

\section{OPSOMMING}

Hierdie studie het die voorkoms van slukprobleme by 'n normale groep bejaardes ondersoek. Vyf-en-twintig aftree-oordinwoners was by hierdie studiegroep ingesluit. ' $n$ Deursnee, beskrywende navorsings-ondersoekplan is gebruik. Gegewens is verkry deur die toepassing van 'n onderhoudprogram. Die voorkoms van slukprobleme in die studiegroep is persentasiegewys bepaal. Die aard van die slukprobleme is ondersoek en vergelyk met dit wat beskryf word in die literatuur. Die bruikbaarheid van die onderhoudprogram is krities geëvalueer. Resultate het getoon dat $44 \%$ van die persone wat slukprobleme ondervind se daaglikse funksionering daardeur beïnloed word. $64 \%$ van die persone het probleme ondervind met die orale, faringale en esofagale fases van die slukproses terwyl $36 \%$ probleme ondervind het met faringale en esofagale fases. Die onderhoud was 'n nuttige siftingsmetode om die aanwesigheid van slukprobleme te identifiseer. Die rol van die spraakpatoloog in disfagie onder die gewone bejaarde bevolking word beklemtoon en geregverdig.

KÉY WORDS: swallowing problem, normal ageing, screening interview

"Swallowing impairment increases in prevalence with advancing age and is a major health care problem in the aged" (Ekberg \& Feinberg, 1991, p. 1181). Recent literature suggests that the swallow undergoes changes during the normal ageing process that can lead to swallowing problems (Logemann, 1990; Robbins et al., 1992; Ward et al., 1989; Sheth and Diner, 1988; Sonies et al., 1988; Tracy et al., 1989). In order to understand the impact of swallowing disorders, it is necessary to develop an appreciation of the clinical problem, both for the individual patient and for society as a whole (Massey \& Shaker, 1997).

Enjoying a meal or drinking a glass of water are acts that most people take for granted. Swallowing foods or liquids occurs automatically (Kavanaugh, 1994). This is not the case for patients with impaired swallowing. Rather, the fact that dysphagic patients have to remain watchful of such a normally subconscious act as swallowing to avoid discomfort or even death, means that their swallowing disorders greatly interfere with normal living (Massey \& Shaker, 1997). Since mealtime remains the focus of social and interpersonal activity for many elderly persons, disordered swallowing can have a negative impact on the health, nutritional status, self esteem and quality of life of elderly persons (Baker, 1993; Robbins et al., 1992).

The symptoms of dysphagia can be painful and anxiety provoking. They may include the sensation of swallowed substances not going down or going down partially and then sticking (Langley, 1987; Massey \& Shaker, 1997). Dysphagic patients may experience pain or pressure in the throat or chest, which may be so severe that they think it is caused by their hearts. Patients may have to regurgitate a stuck bolus, while at other times material may regurgitate spontaneously. Impaired swallowing can result in coughing and choking while eating. It may also result in food coming out of the nose or in an inability to breathe due to a blocked airway (Kavanaugh, 1994; Massey \& Shaker, 1997).

Patients with swallowing problems often have to modify their diets and eating habits to avoid the above symptoms. Some patients eat so slowly that they are always the last person to finish their meal, if they finish it at all (Massey $\&$ Shaker, 1997). Patients often avoid certain foods because they have learned that these items cause them difficulty (Hildebrandt et al., 1997). Alternatively, patients may attempt to eat problematic foods using compensatory behaviours such as chewing their meat to mush before swallowing or mashing up their food (Lindgren \& Janzon, 1991). 
Despite these efforts, instances of swallowing difficulty inevitably occur. Thus, it is clear that dysphagia can be a socially debilitating condition which adversely affects the person's self-esteem (Bloem et al., 1990; Robbins et al., 1992).

In extreme cases, patients with swallowing difficulties may die from asphyxiation. They may develop aspiration pneumonia, which can be fatal (Feinberg et al., 1990). Dysphagic patients may rupture their alimentary canal by trying to regurgitate a stuck bolus. They may develop severe weight loss and malnutrition, making them more vulnerable to developing infections (Bloem et al., 1990). This is particularly hazardous in the elderly population who is already at a greater risk for mortality (Hildebrandt et al., 1997).

Up to now, the impact of dysphagia on the individual, with special reference to the elderly patient has been discussed. A consideration of the societal burden of swallowing disorders is necessary. Although there is no data available on this issue, the potential exists for a substantial burden from dysphagia on the health care system and a significant economic impact on society as a whole (Massey \& Shaker, 1997). Dysphagic patients often require expensive diagnostic and therapeutic interventions including videofluoroscopy, feeding tube placement and surgery. Thus, the chronic nature of swallowing disorders results in ongoing health care costs (Massey \& Shaker, 1997). This is of particular concern in a country like South Africa, where economic resources are limited.

This study proposed the adaptation of a devised interview schedule (Boolkin, 1998) as a subjective screening tool to identify the presence of swallowing disorders in the elderly population. This inexpensive method of identification may promote the early identification and subsequent early treatment of swallowing disorders, prior to the onset of debilitating and costly complications such as malnutrition and aspiration pneumonia. Since swallowing can involve such serious consequences, it is imperative to identify groups of patients who are at risk for having the disorder. One such group is the elderly population.

The process of ageing brings about changes in the oral, pharyngeal and laryngeal structures, all of which work in synchrony in the swallowing process (Logemann, 1990).

Oral phase changes: According to Logemann (1990), there is an increase in fatty and connective tissue in the tongue with age. Atrophy of the alveolar bone may occur if dentition is lost. There may be an overall decrease in masticatory strength (Sheth \& Diner, 1988). Elderly people exhibit a tendency to hold the bolus more posteriorly in the mouth prior to swallowing (Logemann, 1990). They may have difficulty moving the tongue to control the food (Kavanaugh, 1994). Additional tongue movements have also been noted to occur in the elderly (Sonies et al., 1988). Elderly people may have weak facial muscles causing food to collect in their cheeks. They may have reduced mouth sensations making them unable to feel where food is located in the mouth (Kavanaugh, 1994). In addition, there is a de- crease in the production of saliva with advancing age (Martin, 1991).

Pharyngeal phase changes : The triggering of the pharyngeal phase of the swallow has been found to be delayed in elderly persons and may be as a result of an increase in swallowing threshold with age or to slower neural processing time (Logemann, 1990). The temporal organisation of the pharyngeal phase also appears to be affected. Maximal laryngeal elevation lasts longer and the larynx may descend more slowly. In this way, cricopharyngeal opening is prolonged (Tracy et al., 1989). In addition, Robbins et al. (1992) measured longer pharyngeal transit times. There is delayed clearing of the pharynx due to decreased muscular tonicity (Sheth \& Diner, 1988). The epiglottis is smaller and sharper and is slower to tilt down and backward (Sheth \& Diner, 1988). Elderly persons demonstrate palatal weakness which may result in nasal regurgitation (Kavanaugh, 1994).

Oesophageal phase changes: Muscle tone in the oesophagus may decrease resulting in reduced peristalsis (Sheth and Diner, 1988; Logemann, 1990). Oesophageal transit time is prolonged (Logemann, 1990). Finally, the incidence of hiatus hernias and gastroesophageal reflux is increased with ageing (Sheth \& Diner, 1988).

The issue of normalcy in swallowing is a problematic area of debate. Researchers in swallowing disorders face a formidable challenge in determining appropriate definitions and parameters for normalcy in deglutition (Massey \& Shaker, 1997). For example, if one uses the subjective absence of swallowing problems as a sign of normalcy, this definition will frequently be at odds with objective measures of what is felt to be abnormal swallowing (Massey \& Shaker, 1997). It is not unusual to find a patient aspirating silently without having complaints of swallowing difficulty and no physical indicator such as coughing. Conversely, patients may complain of difficulty swallowing and show no abnormalities in bolus transport on videofluoroscopic measures (Massey \& Shaker, 1997).

Thus making use of objective measures of swallowing parameters to define normalcy may also be problematic. For many of the parameters of swallowing, abnormality may be a matter of degree, rather than a "state-change" from normal to abnormal (Massey \& Shaker, 1997). Thus, a large area of overlap may exist between abnormal and normal populations for a given parameter. Exactly when slow swallowing in the elderly should be considered abnormal remains an area of debate (Robbins, 1995; Massey \& Shaker, 1997). In spite of this, in South Africa, where objective diagnostic measures are not easily accessible, the need to develop and evaluate a subjective device to identify swallowing problems is indicated.

The foregoing discussion has shown that swallowing disorders in general, and in the elderly population specifically, constitutes an important health care problem. The need for intervention in this population has been recognised by speech pathologists in the United States of America and in Britain where they are employed as "swallowing therapists" in nursing homes (Kavanaugh, 1994). However, speech pathologists in South Africa have not followed the above trend. The lack of literature on dysphagia in the elderly population in South African journals supports the view that the role of the speech pathologist in this population is currently underdeveloped in this country.

The purpose of this study therefore was to determine whether normal functioning elderly people experience swallowing difficulties that interfere with their day to day functioning. In so doing, the study aimed to highlight for South African speech pathologists their diagnostic and rehabilitative role in the area of dysphagia with this population. Finally, the study aimed to propose the utilisation of a subjective device to identify the presence of swallowing problems in elderly patients. 


\section{METHODOLOGY}

\section{AIMS}

The aim of the study was to determine whether normal functioning elderly residents in retirement villages experience swallowing difficulties that interfere with their day to day functioning. More specifically, the sub aims were threefold.

- Firstly, to determine the prevalence of swallowing problems in the sample of normal ageing subjects utilising a subjective measure.

- Secondly, to examine the nature of these swallowing problems and to compare them to the nature of swallowing difficulties reported to occur in the normal ageing population.

- Thirdly, to evaluate the usefulness of the devised interview protocol in detecting swallowing problems in elderly patients.

\section{RESEARCH DESIGN}

A cross-sectional descriptive survey constituted the research method (Leedy, 1989). According to Rosner and Rosenthal (1996), "in descriptive research, the goal of investigation tends to be the careful mapping out of a situation or set of events. The research objective is to describe what is happening behaviourally. Causal explanations are not of direct concern except perhaps speculatively" (p. 15).

\section{SUBJECTS}

Subjects were selected based on a number of criteria. Subjects were required to be residents of retirement villages (i.e., not living in frail care). Retirement village residents were selected for the purpose of this investigation because it was felt that this group most adequately reflected normal functioning acrosis the ageing process since they are of sufficiently good health to live and function independently.

An age selection criterion of 65 years and above was stipulated. According to Robbins et al. (1992) the swallow begins to slow from as early as 45 years, although the most noticeable changes occur between 65 and 75 years (Robbins, 1995). No cut-off ceiling was used in the study in order to address a criticism of many previous studies on swallowing in the elderly which have failed to include the oldest old (above 85) in their samples (Logemann, 1990). Subjects were required to be female to exclude the possible variable of gender in the study.

Subjects could only be included in the study if they did not present with any of the following conditions which are common causes of swallowing problems: neurological damage, diseases affecting muscular strength and co-ordination such as muscular dystrophy and cerebral palsy, forms of cancer, progressive neurological disease, injury to face or neck including surgery (Baker, 1993).

Subjects were required to obtain scores that fell within the normal range according to age on the Mini-Mental State Examination (Folstein, Folstein \& McHugh, 1975) in order to rule out the presence of cognitive dysfunction. A score of 25 is the lower limit in the range for normal subjects in the $60-69$ year old age group. A score of 26 is the lower limit in the range for normal subjects in the 70 - 79 year old age group. A score of 24 is the lower limit in the range for normal subjects in the $80-89$ year old age group (Bleeker, Bolla-Wilson, Kawas \& Agnew, 1988). Finally, subjects were required to be able to speak English in order for administration of the interview to be possible.

The subjects are described in Table one. Twenty-five subjects from two retirement villages participated in the study. Subjects ranged in age from 65 to 88 years with a mean age of 77.4 years (S.D. 4.87). The characteristics of diabetes, arthritis and smoking are included in the subject description as this information was required for the interpretation of the results.

Subjects were recruited from two retirement villages. The researcher contacted all subjects and visited each participant at their homes. Informed consent was obtained from each subject.

\section{MEASURING TECHNIQUES}

A structured interview schedule was devised based on a compilation of the literature on swallowing disorders. The interview schedule is available from the authors on request. Questions were adapted from various sources including Boolkin (1998), Langley (1987), Hildebrandt et al., (1997), and Kavanaugh (1994). Questions were chosen to tap five broad areas related to swallowing problems. These areas were the locus of swallowing difficulty (questions aimed at obtaining information pertaining to the oral, pharyngeal and oesophageal phases of the swallow respectively), food avoidance behaviours, the use of strategies to facilitate swallowing, effect of food temperature and consistency on the swallow and consequences of swallowing problems such as weight loss and pneumonia.

Closed and open questions were included in the interview. Closed questions yield information which is easily quantified and ensures comparability of questions across respondents. However, this method of data elicitation leaves little room for unanticipated discoveries and salient issues may be missed (Breakwell, 1996). To provide this information, open-ended questions were included in the interview.

The questionnaire was constructed to address the internal consistency of the subject's responses. Similar questions were posed to the subjects to identify any inconsistencies in the pattern of answers. This served to assess the validity of the data obtained and improves the reliability of interview schedules. Interviewer effects were controlled for in the study by ensuring that the same researcher conducted all the interviews. This promoted consistency in question presentation (Breakwell, 1996).

A pilot study was carried out to address the issue of validity of the interview. This procedure is a data gathering technique that helps define the parameters of the study and provides preliminary warnings and assistance to researchers (Kane, 1985). Modifications to the questionnaire were made based on the results of the pilot study and the final version compiled.

The modified interview schedule was administered to participants and their responses were tape-recorded for later transcription. Subjects who were identified as having swallowing difficulties were referred to a speech pathologist for further management. The Mini-Mental State Examination (Folstein, Folstein \& McHugh, 1975) was administered prior to the interview. 


\section{DATA ANALYSIS}

In order to address the first aim of the study, the percentage of subjects in the sample who experience swallowing problems was computed. The prevalence of swallowing disorders according to age was calculated using percentages.

In order to address the second aim of the study, a profile of the nature of swallowing difficulties experienced by the subjects affecting the oral, pharyngeal and oesophageal phases of the swallow was constructed. The Fisher Exact Test was utilised to identify the presence of statistical relationships between swallowing problems and other variables. This test is an appropriate non-parametric statistic for testing the relationship between two variables if the sample size is small. The Fisher Exact Test computes the exact probability under the null hypothesis of obtaining the current distribution of frequencies across cells, or one that is more uneven (Rosner \& Rosenthal, 1996). A $5 \%$ level of significance $(p<0.05)$ was accepted as indicating significant statistical relationships. Relationships which were significant at the $10 \%$ level $(\mathrm{p}<0.10)$ were also reported due to the exploratory nature of the study (Silverman, 1993).

The third aim of the study was addressed by critically evaluating the usefulness of the interview schedule.

\section{RESULTS AND DISCUSSION}

Results are presented addressing each aim of the study.

\section{PREVALENCE OF SWALLOWING PROBLEMS}

In this study, seven (28\%) of the 25 subjects reported that they experienced difficulty swallowing. Four (16\%) of the subjects who reported that they did not experience difficulty swallowing, demonstrated evidence upon further questioning to suggest that they were in fact experiencing swallowing difficulties. Taking the overall prevalence, $44 \%$ of the subjects were found to experience swallowing problems.

The above finding is clinically relevant since it appears that a substantial proportion of elderly people, who are of sufficiently good health to live and function independently, experience swallowing problems that interfere with their day-to-day functioning. However, it is recognised that the finding of $44 \%$ is only an estimate of true prevalence of swallowing problems in the sample because of the absence of objective measures, such as videofluoroscopy, to confirm pathology.

Groher and Bukatman (1986) completed a review of known prevalence studies of swallowing disorders. Only one study by Trupe, Siebens and Siebens (1984) focussed on swallowing problems in the elderly population. Two subsequent studies, one by Bloem et al. (1990) and the other by Lindgren and Janzon (1991) examined the prevalence of dysphagia in the elderly population. Table 2 presents a comparison between the current findings and these studies.

TABLE 1: Relevant information pertaining to subjects in the study

\begin{tabular}{|c|c|c|c|c|c|c|}
\hline Subjects & Age & Mini-mental Score & Diabetes & Arthritis & Smoker & Ex-smoker \\
\hline 1 & 65 & 28 & & & & \\
\hline 2 & 77 & 29 & & & & \\
\hline 3 & 83 & 26 & & & & \\
\hline 4 & 79 & 29 & 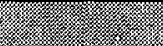 & & & \\
\hline 5 & 80 & 28 & 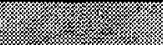 & & & \\
\hline 6 & 77 & 28 & & & & \\
\hline 7 & 77 & 29 & & & & \\
\hline 8 & 77 & 28 & & 1) & & \\
\hline 9 & 77 & 27 & 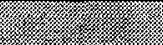 & & & \\
\hline 10 & 82 & 28 & & & & $!$ \\
\hline 11 & 77 & 27 & & 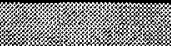 & & $!$ \\
\hline 12 & 80 & 26 & & & & \\
\hline 13 & 77 & 28 & 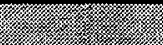 & & & \\
\hline 14 & 79 & 27 & & & & \\
\hline 15 & 74 & 26 & & 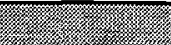 & & \\
\hline 16 & 77 & 29 & & & & 8 \\
\hline 17 & 70 & 28 & & & & 8 \\
\hline 18 & 74 & 26 & & & & . \\
\hline 19 & 88 & 28 & & & & \\
\hline 20 & 74 & 28 & & & & $\therefore$ \\
\hline 21 & 71 & 27 & & & & \\
\hline 22 & 80 & 26 & & & & \\
\hline 23 & 78 & 27 & & & & \\
\hline 24 & 87 & 27 & & & & \\
\hline 25 & 76 & 28 & & & 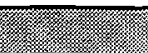 & \\
\hline
\end{tabular}


The current findings, which suggest a prevalence of $44 \%$, are therefore somewhat reduced in comparison to the Trupe et al. (1984) findings and elevated in comparison to the other two studies. A number of possible explanations for the discrepancies exist. Firstly, the different settings of the studies may have influenced the results. Residents in a nursing home are more likely to be ill and in need of frail care. The subjects in the Trupe et al. (1984) study may have been suffering from diseases, which, according to Baker (1993) are direct causes of swallowing problems, such as neurological damage, cancer and diseases affecting muscular strength and co-ordination. These were not controlled for in the Trupe et al. (1984) study which is in contrast to the present study which excluded subjects with these diseases from the sample. Similarly, the other two studies focussed on sectors of the elderly population that are likely to be fairly healthy rather than in need of frail care. Secondly, the difference in sample sizes between the studies needs to be considered. Thirdly, different methods of assessment were used to determine whether swallowing problems were present.

In addition to analysing the prevalence of swallowing problems for the normal ageing sample as a whole, the subjects were divided into three age groups. According to Logemann (1990), investigations on the effects of ageing on the swallow usually categorise persons into one of three age groups (1) the old (65-75 years); (2) the old, old (76-85 years) and (3) the oldest old (over age 85). This convention was followed in an attempt to determine the prevalence of swallowing problems according to age.

One of the $4(25 \%)$ subjects in the old age group reported swallowing difficulties. Ten of the $19(47 \%)$ subjects in the old, old age group reported swallowing difficulties. Neither of the $2(0 \%)$ subjects in the oldest old age group reported swallowing difficulties. These findings are presented in Figure 1.

The current findings indicate that if one ignores the oldest old group, there appears to be a relationship between advancing age and increased prevalence of swallowing impairment. No statistical relationship was demonstrated, however this may be accounted for by the limited size of the sample in the study. The literature on swallowing disorders corroborates the finding that swallowing impairment increases in prevalence with advancing age ( Borgstrom et al., 1988; Groher and Bukatman, 1986).

The fact that no swallowing problems were reported in the oldest old is an interesting finding that does not correspond with the above pattern. A possible explanation may be due to the limited number of subjects in the sample who fell into this age group. The limited representation of this age group in the study may be due to few persons in the oldest old age group living in retirement villages as they tend to no longer be able to function independently.

\section{NATURE OF SWALLOWING DIFFICULTIES IN THE ELDERLY SUBJECTS}

Table 3 presents a summary profile of the nature of the swallowing difficulties experienced by the elderly subjects in the present study. Symptoms are divided according to the three phases of the swallow that may potentially be affected: the oral, pharyngeal and oesophageal phases. The current findings, as highlighted in Table 3 , will be discussed and compared to findings reported in the literature. The overall locus of swallowing difficulties will also be considered.

\section{Oral phase difficulties}

Difficulty with chewing was reported by two of the subjects who experienced swallowing difficulties. One of the subjects reported having to spit lumps of food out during

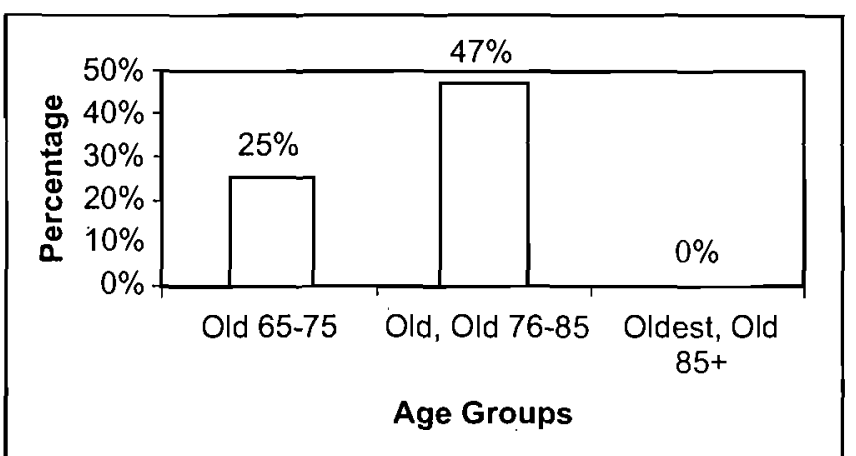

FIGURE 1. Histogram illustrating the prevalence of swallowing difficulties according to age in percentage.

TABLE 2: A comparison ibetween the current findings and those from previous prevalence studies on swallowing disorders in the elderly population.

\begin{tabular}{|l|l|l|l|l|}
\hline & Current Study & Trupe et al. (1984) & Bloem et al. (1990) & $\begin{array}{l}\text { Lindgren and Janzon } \\
(\mathbf{1 9 9 1})\end{array}$ \\
\hline Subject of study & $\begin{array}{l}\text { Prevalence in the } \\
\text { sample }\end{array}$ & Overall prevalence & $\begin{array}{l}\text { Prevalence in a } \\
\text { community }\end{array}$ & $\begin{array}{l}\text { Prevalence in the } \\
\text { general population }\end{array}$ \\
\hline Setting & Retirement villages & Nursing home & $\begin{array}{l}\text { Subjects living in } \\
\text { their own homes }\end{array}$ & Urban population \\
\hline Population & 25 volunteer residents & All residents & $\begin{array}{l}130 \text { elderly persons } \\
(85 \text { years and older) }\end{array}$ & $\begin{array}{l}600 \text { persons between } 50 \\
\text { and 79 years of age }\end{array}$ \\
\hline Method & Interview & $\begin{array}{l}\text { Questionnaire, chart } \\
\text { review, physical exam }\end{array}$ & Interview & Questionnaire \\
\hline Results & $44 \%$ & $50 \%$ & $16 \%$ & $35 \%$ \\
\hline
\end{tabular}


eating. These symptoms may be the result of a decrease in masticatory strength that is reported to occur in the normal ageing population (Logemann, 1990).

Dry mouth was reported by six of the subjects who experienced swallowing difficulties. According to Logemann (1990) and Martin (1991), there is a decrease in the production of saliva with advancing age. In addition, certain medication may interfere with salivary secretions (SchulzeDelrieu \& Miller, 1997).

Only one subject reported food, drink or saliva dribbling from the mouth. According to the literature this may occur as a result of poor mouth closure and reduced oral sensations which occur with ageing (Langley, 1987). Food remaining in the mouth after swallowing was not reported by any of the subjects despite this symptom being reported as a potential difficulty in the elderly population (Kavanaugh, 1994). No statistical relationship was found between the above oral phase symptoms and the presence of swallowing difficulties.

\section{Pharyngeal phase difficulties}

Difficulty initiating a swallow was reported by 7 of the subjects who experienced difficulty swallowing. The relationship between experiencing difficulty initiating a swallow and the presence of a swallowing problem was significant ( $p=0.000686$ by Fisher Exact Test). This finding is supported by reports in the literature that the triggering of the pharyngeal phase of the swallow is delayed in elderly persons (Logemann, 1990; Kavanaugh, 1994).

The need to swallow more than once on a single mouthful of food was reported by 7 of the subjects. This symptom may also be related to the delayed triggering of the pharyngeal phase of the swallow that occurs with age (Kavanaugh, 1994). The relationship between swallowing more than once on a single mouth of food and the presence of a swallowing problem was significant $(p=0.0072$ by Fisher Exact Test).
The need to wash food down with liquids was reported by 5 of the subjects who experienced swallowing difficulties. The relationship between washing food down with liquids and the presence of a swallowing problem was significant ( $p=0.0087$ by Fisher Exact Test). This behavioural method of compensation may be enacted in order to attempt to assist the pharyngeal phase of the swallow to occur since it may be delayed in elderly persons (Kavanaugh, 1994).

Taking time to swallow was reported by 7 of the subjects who experienced swallowing problems. The relationship between taking time to swallow and the presence of swallowing difficulties was significant $(p=0.017$ by Fisher Exact Test). The literature supports the finding of slower swallows in the elderly (Robbins et al., 1992; Sonies et al., 1988).

Coughing during eating was reported by 5 of the subjects who experienced swallowing difficulties. The relationship between coughing during eating and the presence of swallowing difficulties was significant ( $p=0.056$ by Fisher Exact Test). Choking while eating was reported by 4 of the subjects demonstrating a significant relationship with swallowing problems ( $p=0.0087$ by Fisher Exact Test). The above symptoms may occur as a result of defective closure of the larynx due to difficulty co-ordinating the muscles that close and protect it, which is reported to occur with age (Kavanaugh, 1994; Schulze-Delrieu and Miller, 1997).

One subject reported the experience of a wet sounding or gurgly voice when eating. This is commonly reported as a symptom of dysphagia in the elderly (Kavanaugh, 1994) and in general in dysphagic patients (Martin, 1991). No statistical relationship was found between the experience of a wet voice and the presence of a swallowing problem.

Food coming through the nose was not reported by any of the subjects despite this symptom being reported as a potential difficulty in the elderly (Kavanaugh, 1994).

TABLE 3: Summary profile of the nature of swallowing difficulties reported to be experienced by the elderly subjects in the present study

\begin{tabular}{|c|c|c|c|c|c|c|c|c|c|c|c|c|c|c|c|c|}
\hline \multirow[b]{2}{*}{ Subject } & \multicolumn{4}{|c|}{ ORAL } & \multicolumn{7}{|c|}{ PHARYNGEAL } & \multicolumn{5}{|c|}{ OESOPHAGEAL } \\
\hline & $\begin{array}{c}\text { Diffi- } \\
\text { culty } \\
\text { chewing }\end{array}$ & $\begin{array}{l}\text { Dry } \\
\text { mouth }\end{array}$ & $\begin{array}{c}\text { Food/ } \\
\text { Drink } \\
\text { Dribbles } \\
\text { from } \\
\text { mouth }\end{array}$ & $\begin{array}{c}\text { Spit } \\
\text { lumps } \\
\text { of food } \\
\text { out }\end{array}$ & $\begin{array}{c}\text { Diffi- } \\
\text { culty } \\
\text { initia- } \\
\text { ting } \\
\text { swallow }\end{array}$ & $\begin{array}{c}\text { Taking } \\
\text { time } \\
\text { to } \\
\text { swallow }\end{array}$ & $\begin{array}{c}\text { Swallox } \\
\text { more } \\
\text { than } \\
\text { once }\end{array}$ & $\begin{array}{c}\text { Cough } \\
\text { while } \\
\text { eating }\end{array}$ & $\begin{array}{l}\text { Choke } \\
\text { while } \\
\text { eating }\end{array}$ & $\begin{array}{l}\text { Wet } \\
\text { voice } \\
\text { after } \\
\text { eating }\end{array}$ & $\begin{array}{l}\text { Wash } \\
\text { food } \\
\text { down } \\
\text { with } \\
\text { liquid }\end{array}$ & $\begin{array}{c}\text { Feeling } \\
\text { of food } \\
\text { catching }\end{array}$ & $\begin{array}{l}\text { Pain } \\
\text { behind } \\
\text { breast } \\
\text { bone }\end{array}$ & $\begin{array}{c}\text { Food } \\
\text { comes } \\
\text { back up } \\
\text { throat }\end{array}$ & $\begin{array}{l}\text { Want to } \\
\text { be sick } \\
\text { after } \\
\text { cating }\end{array}$ & $\begin{array}{l}\text { Heart- } \\
\text { burn }\end{array}$ \\
\hline & & & (2) & $\sqrt[3]{2}$ & & & & & 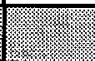 & & 12 & & 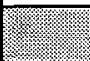 & & & \\
\hline 1 & & 21:- & & & & & & : & ?.8. & & & & & & & 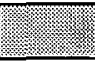 \\
\hline 17 & & & & & & & & & & & & & 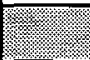 & & & \\
\hline & & & & & 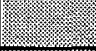 & & & 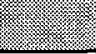 & (2.1) & 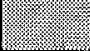 & & & $\sqrt{2}$ & & & \\
\hline 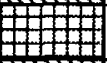 & & & & & & & & & & & & & & 17. & & \\
\hline & 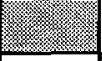 & & & & 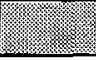 & & & 8 & & & & & & $1 \%$ & & \\
\hline & & & & & & & & & 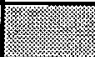 & & & 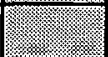 & & & & \\
\hline & & & & & 2 & & & & & & & & 2 & , & & \\
\hline & & & & & & 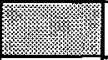 & & & & & & 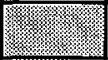 & & & & .8 \\
\hline & & & & & & & 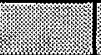 & 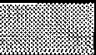 & & & 2 & 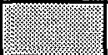 & 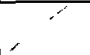 & & & 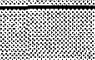 \\
\hline \#\#丮 & & & & & & & & & & & & & & & & \\
\hline
\end{tabular}

Key: Subjects who perceive themselves to have swallowing problems.

Subjects who did not perceive themselves to have swallowing problems 


\section{Oesophageal phase difficulties}

Nine subjects reported that they experienced the sensation of food catching below the level of the larynx. The relationship between the sensation of food catching and the presence of swallowing difficulties was significant ( $p=0.0000269$ by Fisher Exact Test). Reduced or less efficient peristalsis due to a decrease in muscle strength may occur with ageing (Sheth \& Diner, 1988; Logemann, 1990). This may account for the sensation of food catching in the oesophagus.

Four of the subjects reported experiencing pain behind the breastbone after eating. The relationship between this symptom and swallowing difficulties was significant ( $p=0.026$ by Fisher Exact Test). Four of the subjects reported that food comes back up their throat during eating A statistically significant relationship was demonstrated between the presence of swallowing difficulties and food coming back up the throat ( $\mathrm{p}=0.056$ by Fisher Exact Test). The incidence of hiatus hernia and gastric reflux is increased with advancing age (Sheth \& Diner, 1988) and may account for the two symptoms described above.

Two of the subjects reported that they feel like being sick after eating. Five of the subjects reported that they experience heartburn frequently. Although these two symptoms are reported in the literature as indicators of swallowing problems (Langley, 1987), no statistical relationship between these symptoms and the presence of swallowing difficulties was demonstrated.

\section{Overall locus of swallowing difficulties}

The current findings indicate that $64 \%$ of the subjects appear to have difficulties that affect all three stages of the swallow. $36 \%$ of the subjects appear to have difficulties affecting both the pharyngeal and oesophageal phases of the swallow. These findings, presented in Table 4, may be compared to two studies by Feinberg and Ekberg (1991) and Ekberg and Feinberg,(1991) in which the locus of swallowing difficulty in the samples was determined.

The differences in percentages in the above studies may be accounted for by the differences in the populations studied, the difference in the sample sizes and the different meth- ods of assessment to determine the nature of the swallowing difficulties. However, the current finding that difficulties affecting oral, pharyngeal and oesophageal phases are experienced by elderly people is supported by the Ekberg and Feinberg (1991) and Feinberg and Ekberg (1991) studies.

\section{USEFULNESS OF THE INTERVIEW SCHEDULE}

The devised interview schedule successfully detected symptoms of swallowing problems in 11 of the 25 subjects. As mentioned earlier, only 7 of these subjects perceived themselves as experiencing difficulty swallowing. Four of the subjects who did not perceive themselves as having swallowing difficulties demonstrated evidence to suggest that they were in fact experiencing swallowing problems.

The above discrepancy may be viewed as indicative of the usefulness of the interview in detecting swallowing problems in elderly persons, including those who are either unaware of the difficulties or have not considered them to be a problem. However, it is important for the clinician to exercise caution and avoid giving dysphagia to those who do not have it (Robbins, 1995).

Apart from detecting the presence of swallowing difficulties, the interview schedule provided information regarding symptomatology relating to the various phases of the swallow. Information regarding the locus of the swallowing problem, oral, pharyngeal and oesophageal, was gleaned. However, it is important to note that the information obtained was based on the perceptions of the individual subjects and is highly subjective. Further investigations involving objective measures would be necessary to confirm the locus of pathology and to determine the severity of the problem.

For the above reasons it would seem appropriate to make use of the interview as an initial screening measure in determining the presence of a swallowing problem. The interview may highlight the need for further investigations such as the bedside evaluation and videofluoroscopic examination. The use of the interview as a screening tool may be of particular value in the South African context where resources are limited and advanced diagnostic measures such as videofluoroscopy are expensive and often inaccessible.

The interview schedule proved useful in terms of high-

TABLE 4: A comparison of current findings regarding locus of swallowing difficulties with findings from two studies: Feinberg and Ekberg (1991) and Ekberg and Feinberg (1991).

\begin{tabular}{|l|l|l|l|}
\hline & Current Study & $\begin{array}{l}\text { Feinberg and Ekberg } \\
(\mathbf{1 9 9 1})\end{array}$ & $\begin{array}{l}\text { Ekberg and Feinberg } \\
(\mathbf{1 9 9 1})\end{array}$ \\
\hline Population & $\begin{array}{l}\text { 25 normal functioning retirement } \\
\text { village residents }\end{array}$ & 50 patients known to aspirate & $\begin{array}{l}56 \text { persons with no symptoms of } \\
\text { dysphagia or eating difficulty }\end{array}$ \\
\hline Mean age & 77.4 years & 87 years & 83 years \\
\hline Method & Interview & Videofluroscopy & Videofluroscopy \\
\hline Results & $\begin{array}{l}\text { 64\% with difficulties involving } \\
\text { all three phases of the swallow. } \\
36 \% \text { with difficulties involving } \\
\text { both the pharyngeal and } \\
\text { oral phases. } \\
\text { 0\% with difficulties in only } \\
\text { one phase. }\end{array}$ & $\begin{array}{l}46 \% \text { abnormalities of oral stage. } \\
\text { geal phase. } \\
34 \% \text { abnormalities of oral and } \\
\text { pharyngeal phase. }\end{array}$ & $\begin{array}{l}63 \% \text { oral abnormalities. } \\
25 \% \text { pharyngeal abnormalities } \\
\text { abnormalities. } \\
36 \% \text { oeophageal abnormalities }\end{array}$ \\
\hline
\end{tabular}


lighting a number of other factors either related or not related to swallowing problems in the elderly. These included diabetes, arthritis, smoking, use of dentures, food avoidance patterns, food consistency, difficulty swallowing tablets, use of "tricks" during eating and aspiration pneumonia. A discussion of these findings follows.

Diabetes, arthritis and smoking : No statistical relationship was found between subjects with diabetes and the presence of swallowing problems despite reports in the literature that diabetic subjects frequently experience dysphagia (Boolkin, 1998). The small sample size may account for the absence of this finding. Similarly, no relationship between subjects with arthritis and the presence of swallowing difficulties was found. Smoking was also not found to be related to the presence of swallowing problems. However, the limited sample size may account for the absence of these relationships.

Dentures: No statistical relationship was found between the use of dentures and the presence of swallowing problems. This finding is in contrast to a study by Hildebrandt et al. (1997) which found that compromised dental function, including the use of prostheses, results in the swallowing of poorly chewed food, food avoidance patterns and dietary inadequacies. The limited sample size may account for the contrasting findings.

Food avoidance patterns: The relationship between food avoidance and the presence of swallowing problems was significant ( $p=0.000983$ by Fisher Exact Test). Adequate nutritional intake is of great medical importance in the elderly (Hildebrandt et al., 1997). The individual's ability to comfortably swallow certain food types is an important component of nutritional intake. Current findings indicate that the swallowing difficulties experienced by the subjects impact on their diets to the extent that particular foods are avoided.

Avoidance of chewy foods (such as beef and steak) and crunchy food (such as vegetables) was reported by four of the subjects, however this was not found to be statistically significant. Meat and vegetables are important dietary sources of protein, iron, vitamins and fibre. Careful monitoring of sufficient intake of these food types is critical in the elderly patient (Hildebrandt et al., 1997) Avoidance of crumbly foods (such as biscuits or cake) and dry foods (such as bread) was statistically related to swallowing problems ( $p=0.026$ and $p=0.072$ respectively by Fisher Exact Test). Crumbly foods fall apart in the mouth and are reportedly more difficult to swallow (Langley, 1987).

According to Hildebrandt et al.(1997), involuntary weight loss may occur as a result of food avoidance's and is a risk indicator for mortality in the elderly. Although the elderly subjects in the present study commonly reported weight loss, it was often ascribed to other factors such as illness, depression and diabetes.

Difficulty swallowing tablets: The relationship between difficulty swallowing tablets and the presence of swallowing problems was significant ( $p=0.082$ by Fisher Exact Test). This finding is of concern since many elderly people are reliant on medication for their wellbeing. If elderly patients struggle to swallow tablets they may avoid taking their medication which could have detrimental consequences (Massey \& Shaker, 1997). This may be an area where altered medicine preparations may be warranted to facilitate compliance in elderly people in taking their medication.

Use of "tricks"during eating: Many of the subjects with swallowing difficulties reported making use of certain "tricks" to help them eat more efficiently. These included sitting up straight while eating, cutting food finely, chewing very well, mashing up food and grating fruit and vegetables, taking liquid with all food, moistening all food with spreads and gravy, eating slowly and concentrating carefully on swallowing. These "tricks" indicate that the subjects are engaging in compensatory behaviours in order to cope with their difficulties. Most of these seem to be positive adaptations to the changes in their swallowing abilities.

Food consistency: Subjects with swallowing difficulties reported that it is easier to swallow mincemeat in comparison to steak. The relationship was significant ( $p=0.033$ by Fisher Exact Test). This finding is in contrast to reports in the literature, which suggest that crumbly foods with uneven consistency are more difficult to swallow. The extra effort necessary to chew. steak and the corresponding decrease in masticatory strength that occurs with ageing (Logemann, 1990) may account for the above finding.

Pneumonia: No relationship between the presence of swallowing problems and the experience of pneumonia was found. Pneumonia is a commonly reported symptom of dysphagia (Feinberg et al., 1990; Massey \& Shaker, 1997). The relatively mild nature of the swallowing difficulties experienced by the elderly subjects may account for the absence of this finding.

The prevalence and nature of swallowing impairment in the normal ageing population and the related factors found in this study have implications for the individual, society and the clinician.

\section{CONCLUSION}

The study showed that a substantial proportion of the sample of elderly subjects experience swallowing problems that interfere with their day to day functioning. The nature of these difficulties was described and findings indicated that

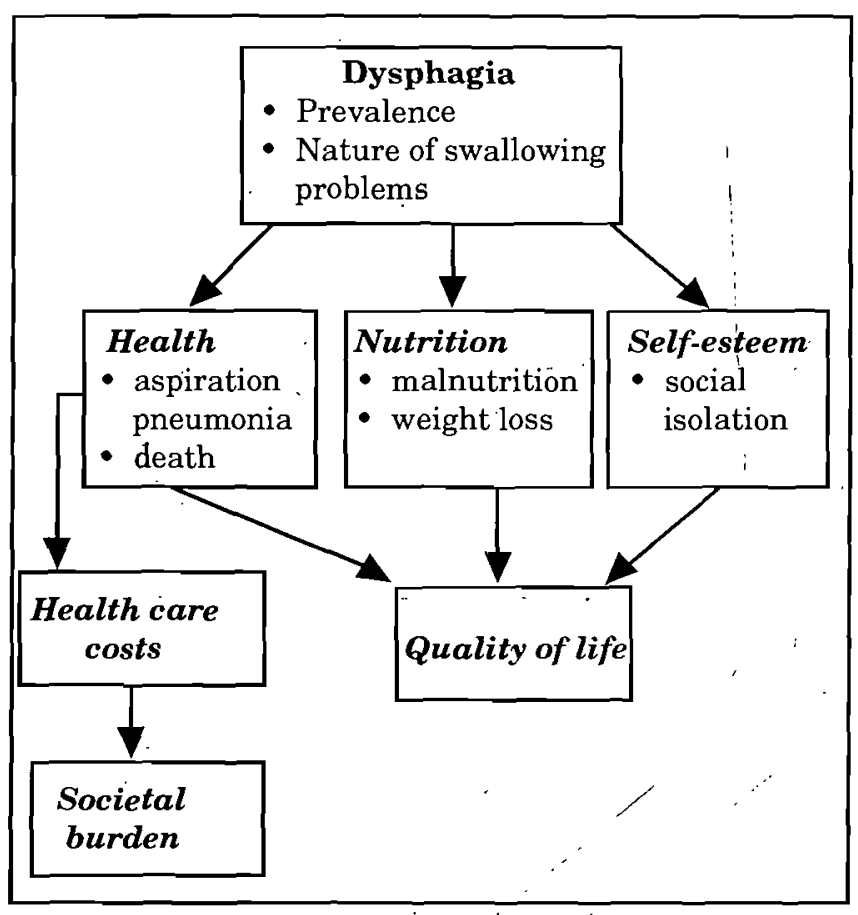

FIGURE 2: Diagrammatic representation of the impact of dysphagia on the elderly person and on society. 
$64 \%$ of the subjects experienced difficulties affecting all three phases of the swallow while $36 \%$ experienced difficulties affecting the oesophageal and pharyngeal phases of the swallow. This study demonstrated the utility of the devised interview schedule as an inexpensive means of detecting swallowing problems in the South African elderly population, where objective measures are inaccessible.

A number of theoretical implications arise from this study. In order to understand the importance of the field of dysphagia, it is necessary to have an appreciation of the clinical problem, both for the individual patient and for society as a whole (Massey \& Shaker, 1997). A model of the implications of dysphagia for the elderly individual and society at large is presented in Figure 2

The prevalence and nature of swallowing impairment can have a negative impact on the health of the elderly to the extent that complications, such as aspiration pneumonia develop which can lead to death (Feinberg et al., 1990). Dysphagia can negatively affect the nutritional status of the elderly person which may result in malnutrition and severe weight loss (Bloem et al., 1990). These are risk indicators for mortality in the elderly (Hildebrandt et al., 1997). Finally, disordered swallowing may negatively impact on the elderly person's self-esteem and may lead to social isolation because of an unwillingness to eat in front of others (Bloem et al., 1990). This is often exacerbated in elderly persons due to the importance of mealtime as a social and interpersonal activity (Baker, 1993). The impact of dysphagia on the health, nutritional status and self-esteem of the elderly person all negatively impact on the quality of life of these individuals (Massey \& Shaker, 1997).

The impact of dysphagia on the health of the individual, the chronic nature of the difficulty and the need for expensive diagnostic and therapeutic interventions implies a substantial burden on the health care system and a significant economic impact on society as a whole. The need for early identification and treatment of dysphagia to prevent the onset of costly complications cannot be overstated in an economically limited country like South Africa.

A further theoretical implication of the study relates to the issue of normalcy in swallowing. As discussed in the introduction, determining appropriate definitions for normalcy and accurate means for assessing the presence of swallowing problems remains problematic for researchers in the field of swallowing disorders (Massey \& Shaker, 1997). In South Africa, costly objective measures are not easily accessible. There is a need to develop and evaluate a subjective device to identify the presence of swallowing disorders. The present study has attempted to address this need by proposing the use of the devised interview schedule as a dysphagia screening measure. This device was able to detect the presence of swallowing problems. However, it was unable to further clarify the debate surrounding appropriate definitions for normalcy. Perhaps the model in Figure 3 suggests a way to approach the issue of normalcy, that is, by evaluating the extent to which the patient's quality of life is affected. Therefore, rather than just attempting to define normal versus disordered swallowing, an instrument which measures the handicapping effect of this swallowing difficulty on quality of life may be indicated.

The findings of the study raise clinical implications. The role of the speech pathologist in the area of dysphagia in the normal ageing population is highlighted and justified. A large proportion of subjects who could potentially benefit from diagnostic and therapeutic interventions specific to their swallowing disorders was identified.

It is the responsibility of the speech pathologist to promote the identification and treatment of swallowing disorders in the elderly population. This is of particular importance in the South African context, where the role of the speech pathologist in dysphagia in the elderly population is currently underdeveloped. South African speech pathologists are urged to address the need by promoting our services with this population in old age homes and retirement villages.

The interview schedule is a device that can be administered by speech pathologists and other health care professionals who have contact with elderly people. Most retirement villages and old age homes have medical clinics on the premises. Healthcare-workers employed in these clinics should administer the interview to patients who attend the clinic in order to detect swallowing problems. A speech pathologist could then be called in to intervene with further diagnostic measures and therapeutic techniques.

From a clinical perspective, it is therefore hoped that South African speech pathologists will embrace their role in working with elderly subjects with swallowing difficulties - an area that is overlooked at present:

The present study had a number of limitations that included the following. The limited sample size makes generalisability of the results difficult. Response bias may have been introduced into the study in that subjects with symptoms of swallowing difficulty may have been more willing to participate in the study (Massey \& Shaker, 1997). This may have resulted in over-representation of the findings. Finally, the validity of the questionnaire as an assessment tool is a problematic issue because of its subjective nature and the lack of consensus about normalcy in swallowing in the literature. The need to develop a device which measures the effect of swallowing impairment on quality of life is indicated.

The results of the study provide several implications for future research. Ongoing research into this population using larger samples is necessary in order to add strength to the current findings regarding the prevalence of swallowing difficulties in the normal ageing population. The current findings should be compared to findings from objective measures such as videofluoroscopy, in order to substantiate the findings and to determine the sensitivity and reliability of the interview schedule. Investigation of the social ramifications of swallowing problems and the development of a device which measures the impact of swallowing impairment on the quality of life of the individual is necessary.

In conclusion, this study has served to highlight the diagnostic and rehabilitative role of speech pathologists in the area of dysphagia in the normal ageing population. It is hoped that as South African speech pathologists, we will begin to meet the challenge of asserting our role as "swallowing therapists" with the normal ageing population. In so doing, we may effectively improve the wellbeing and quality of life of our elderly patients. "The magnitude of the dysphagia burden for individual patients and society at large is ample reason.... to strive to meet these challenges" (Massey \&Shaker, 1997, p. 11).

\section{REFERENCES}

Baker, D.M. (1993). Assessment and management of impairments in swallowing. Nursing Clinics of North Anerica, 28 (4), 793805 . 
Bleeker, M.L., Bolla-Wilson, K., Kawas, C. and Agnew, J. (1988). Neurology, 38, 1566 .

Bloem, B.R., Lagaay, A.M., van Beek, W., Haan, J., Roos, R.A.C., Wintzen, A.R. (1990). Prevalence of subjective dysphagia in community residents aged over 87. British Medical Journal, $300,721-722$.

Boolkin, L. (1998). The incidence of dysphagia in diabetic patients. Unpublished Masters research report, University of the Witwatersrand, Johannesburg.

Borgstrom, P.S. and Ekberg, O. (1988). Pharyngeal dysfunction in the elderly. Journal of Diagnostic Imaging, 2, 74-81.

Breakwell, G. (1996). Research methods in psychology. London, Sage.

Ekberg, O. and Feinberg, M.J. (1991). Altered swallowing function in elderly patients without dysphagia: radiologic findings in 56 cases. American Journal of Roentology, 156 (6), 11811184 .

Feinberg, M.J. and Ekberg, O. (1991). Videofluoroscopy in elderly patients with aspiration: importance of evaluating both oral and pharyngeal stages of deglutition. American Journal of Radiology, 156 (2), 293-296.

Feinberg, M.J., Knebl, J., Tully, J., Segall, L. (1990). Aspiration and the elderly. Dysphagia $5,61-71$.

Folstein, M.F. Folstein, S.E. and McHugh, P.R. (1975). MiniMental State: A practical method for grading the cognitive state of patients for the clinician. Journal of Psychiatric Research, 12, 196-198.

Groher, M.E. and Bukatman, R. (1986). The prevalence of swallowing disorders in two teaching hospitals. Dysphagia, 1, 3-6.

Hildebrandt, G.H., Dominguez, B.L. Schork, M.A., Loesche, W.J. (1997). Functional units, chewing, swallowing and food avoidance among the elderly. Journal of Prosthetic Dentistry, 77 (6), 588-595.

Kane, E. (1985). Doing your own research: Basic descriptive research in the social sciences and humanities. London, Marion Boyars.

Kavanaugh, K.M. (1994). "Understanding and treating swallowing problems". Chicago, IL. Illinois Council on Long Term Care.

Langley, J. (1987). Working with swallowing disorders. Winslow press, Oxon.

Leedy, P.D. (1989). Practical Research: Planning and design. $5^{\text {th }}$ edition, Macmillan, New York.

Lindgren, S. and Janzon, L. (1991). Prevalence of swallowing complaints and clinical findings among $50-79$ year old men and women in an urban population. Dysphagia, 6, 187-192.

Logemann, J.A. (1990). Effects of ageing on the swallowing mechanism: Head and neck diseases in the elderly. Otolaryngologic Clinics of North America, 23 (6), 1045-1056.

Martin, A.W. (1991). Dietary management of swallowing disorders. Dysphagia, 6, 129-134.

Massey, B.T. and Shaker, R. (1997) "Introduction to the field of deglutition and deglutition disorders" Chapter 1 in Perlman, A.L. and Schulze-Delrieu, K.S. (Eds.) Deglutition and its disorders. Anatomy, physiology, clinical diagnosis and management. Singular Publishing Group, Inc., San Diego.

Robbins, J. (1995). Translating current research into clinical practice: Physiology of swallowing. ASHA: Special Interest Division: Swallowing and swallowing disorders (Dysphlagia) 4 (3), Nov, 7-10.

Robbins, J., Hamilton, J.W., Lof, G.L. and Kempster, G.B. (1992). Oropharyngeal swallowing in normal adult of different ages. Gastroenterology, 103, 823-837.

Rosner, R.L. and Rosenthal, R. (1996). Beginning behavioural research: A conceptual primer. $2^{\text {nd }}$ edition. Prentice Hall, London.

Schulze-Delrieu, K.S. and Miller, R.M. (1997) "Clinical assessment of dysphagia" Chapter 5 in Perlman, A.L. and SchulzeDelrieu, K.S. (Eds.) Deglutition and its disorders. Anatomy, physiology, clinical diagnosis and management. Singular Publishing Group, Inc., San Diego.

Sheth, N. and Diner, W.C. (1988). Swallowing problems in the elderly. Dysphagia, 2, 209-215.

Silverman, F.H. (1993). Research design and evaluation in speech. language pathology and audiology: asking and answering questions. Prentice Hall, Englewood Cliffs.

Sonies, B., Parent, L., Morrish, K., et al. (1988). Durational aspects of the oral-pharyngeal phase of the swallow in normal adults. Dysphagia, 3, 1-10.

Tracy, J.F., Logemann, J.A., Kahrilas, P.J., Jacob, P., Kobara, M. Krugler, C. (1989). Preliminary observations on the effects of age on oropharyngeal deglutition. Dysphagia, 4, 90-94.

Trupe, E.H., Siebens, H., Siebens, A. (1984). Prevalence of feeding and swallowing disorders in a nursing home. Arch Phys Med Rehabil, 65, 651-652.

Ward, P.H., Colton, R., McConell, F., Malmgren, L., Kashima, H., Woodson, G. (1989). Aging of the voice and swallowing. Otolaryngology and Head and Neck Surgery, 100 (4). 283-286. 